\title{
Total Hip Arthroplasty: Past, Present, and Future. What Has Been Achieved?
}

\author{
Won Yong Shon, MD, PhD, Beyoung-Yun Park, MD, Rajsankar N R, MD, \\ Phil Sun Park, MD*, Jung Taek Im, MD*, Ho Hyun Yun, MD, PhD* \\ Department of Orthopedic Surgery, Bumin Hospital, Busan, Korea \\ Department of Orthopedic Surgery, Veterans Health Service Medical Center, Seoul, Korea*
}

In the 1960s, Sir John Charnley introduced to clinical practice his concept of low-friction total hip arthroplasty (THA). Although early designs were plagued by poor performance and even failure, there have been steady advances in implant designs, biomaterials, surgical techniques and an understanding of the biomechanical restoration of the hip; these advances have contributed to improvements in implant survival and clinical outcomes of THA in the past three decades. With improved wear resistance and mechanical reliability, a potential to last for at least 25 to 30 years are now available for THA. In this review, we focus on the evolution of THA and review current controversies and future directions of this procedure based on a single surgeon's 29year of experience at a single institution.

Key Words: Total hip arthroplasty, Acetabular cup, Femoral stem, Bearing surface, Impingement

\section{INTRODUCTION}

The first published reports of hip arthroplasty date as far back as the $1940 \mathrm{~s}^{1,2}$. In the 1960s, Sir John Charnley introduced to clinical practice his concept of low-friction total hip arthroplasty (THA) ${ }^{3,4}$. The early results of THA with and without bone cement were disappointing ${ }^{5-12)}$

Submitted: July 5, 2019 1st revision: September 3, 2019

Final acceptance: September 16, 2019

Address reprint request to

Ho Hyun Yun, MD, PhD

[https://orcid.org/0000-0003-3628-9047]

Department of Orthopedic Surgery, Veterans Health Service

Medical Center, 53 Jinhwangdo-ro 61-gil, Gangdong-gu, Seoul

05368, Korea

TEL: +82-2-2225-1114 FAX: +82-2-2225-1461

E-mail: 3188yunanaver.com

This is an Open Access article distributed under the terms of the Creative Commons Attribution Non-Commercial License (http://creativecommons. org/licenses/by-nc/4.0) which permits unrestricted non-commercial use, distribution, and reproduction in any medium, provided the original work is properly cited due to the poor design of implants, undersized femoral components, poor cementing technique, periprosthetic osteolysis and excessive wear of the polyethylene liner. However, there have been steady advances in THA over the last three decades (e.g., improved understanding of cementing techniques, better acetabular and femoral component design, refined implantation surgical techniques) leading to significant improvements in implant survival and clinical outcomes. THA is considered a landmark surgery in modern medical history and the clinical results over the last 30 years have proven that it is one of the most effective and successful surgical techniques for treating various pathological hip conditions ${ }^{13}$.

This review summarizes the history, current controversies and future directions of THA in order to highlight and address issues that are key to: i) improving clinical outcomes today and ii) guide future advancements and improvements on the success of this surgical technique. The information presented here is based on the experience of the author and his more than 29 years of experience performing THAs at a single institution. 


\section{Hip \& Pelvis}

Hip Pelvis 31(4): 179-189, 2019

\section{THE PAST}

In 1990, the author began clinical practice using hybrid THA $^{14)}$-a variation of Charnley's low-friction THA $^{3)}$ that employs cemented and cementless fixation of the femoral and acetabular components, respectively. Initially, the majority of implants were first-generation ${ }^{15-18}$ hemispherical porous acetabular cups (Harris-Galante; Zimmer, Warsaw, IN, USA) and Precoat ${ }^{14,19)}$ femoral stems (Harris Precoat Plus; Zimmer) (Fig. 1) with conventional non-cross-linked ultra-high molecular weight polyethylene (UHMWPE) liners ${ }^{20,21}$. Implants were selected based on several factors: i) despite excellent mid-term clinical results of cemented cups, these components were associated with unacceptably

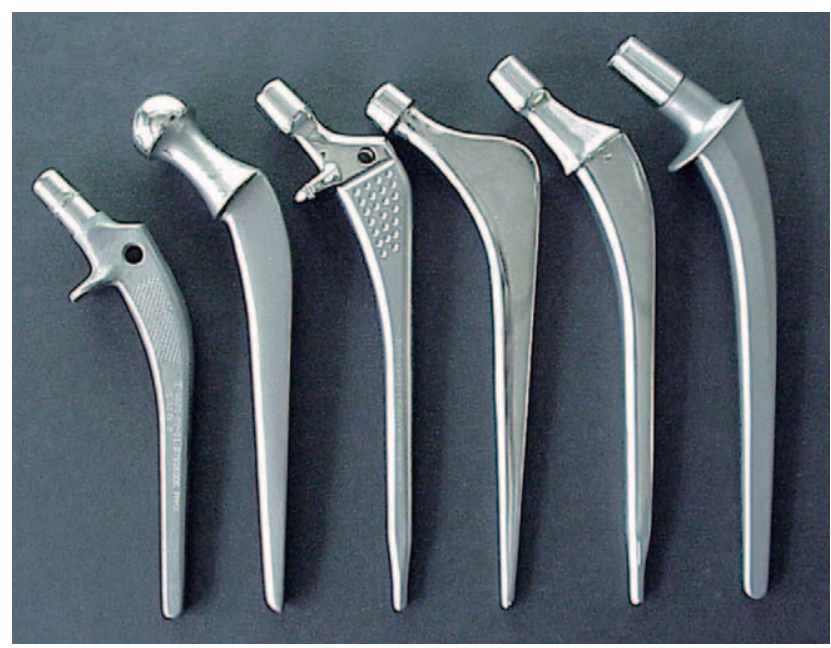

Fig. 1. Various cemented femoral stems. The Precoat Plus stem is located in the most left-hand corner of the image. high failure rates upon long-term follow-up ${ }^{22,23)}$, ii) the size of Precoat stems was suitable for the majority of the smaller Asian population, such as Koreans, and iii) conventional non-cross-linked UHMWPE ${ }^{20,21)}$ was the most widely used liner biomaterial during that time.

A review of the author's early series of 76 primary hybrid THAs with a mean follow-up of 15.5 years (range, 14-19.5 years $)^{14)}$, there were $23(30.3 \%)$ acetabular reoperations (isolated acetabular liner exchange, 12 cases; cup revision, 11 cases) with an average duration to revision of 11.5 years. The survival rate of the acetabular component was $91.5 \%$ at 10 years, $72.0 \%$ at 15 years, and $45.3 \%$ at 19 years, results which are similar to other analyses of first-generation cementless cups ${ }^{15-18}$. Based on studies of cementless acetabular cups, press-fit fixation of the cup was recommended. The most common reason for acetabular reoperations was excessive polyethylene liner wear and osteolysis secondary to polyethylene particulate debris (Fig. 2), which were the most notable factors endangering the long-term survivorship of THA ${ }^{21,24)}$. Although the cementless hemispherical cup had good fixation ability, its ability to survive for 20 years was difficult due to wear and wear-related osteolysis (Fig. 3).

Of the 76 Precoat femoral stems ${ }^{16)}, 24$ femoral stems (31.6\%) experienced aseptic loosening with an average duration of eight years until need for revision surgery even with the use of the modern third-generation cementing techniques (i.e., pulsatile lavage, cement restrictor, retrograde canal filling and pressurization with a cement gun, reduced cement porosity by vacuum mixing ${ }^{25}$. Twentyone out of 24 cases of femoral stem aseptic loosening
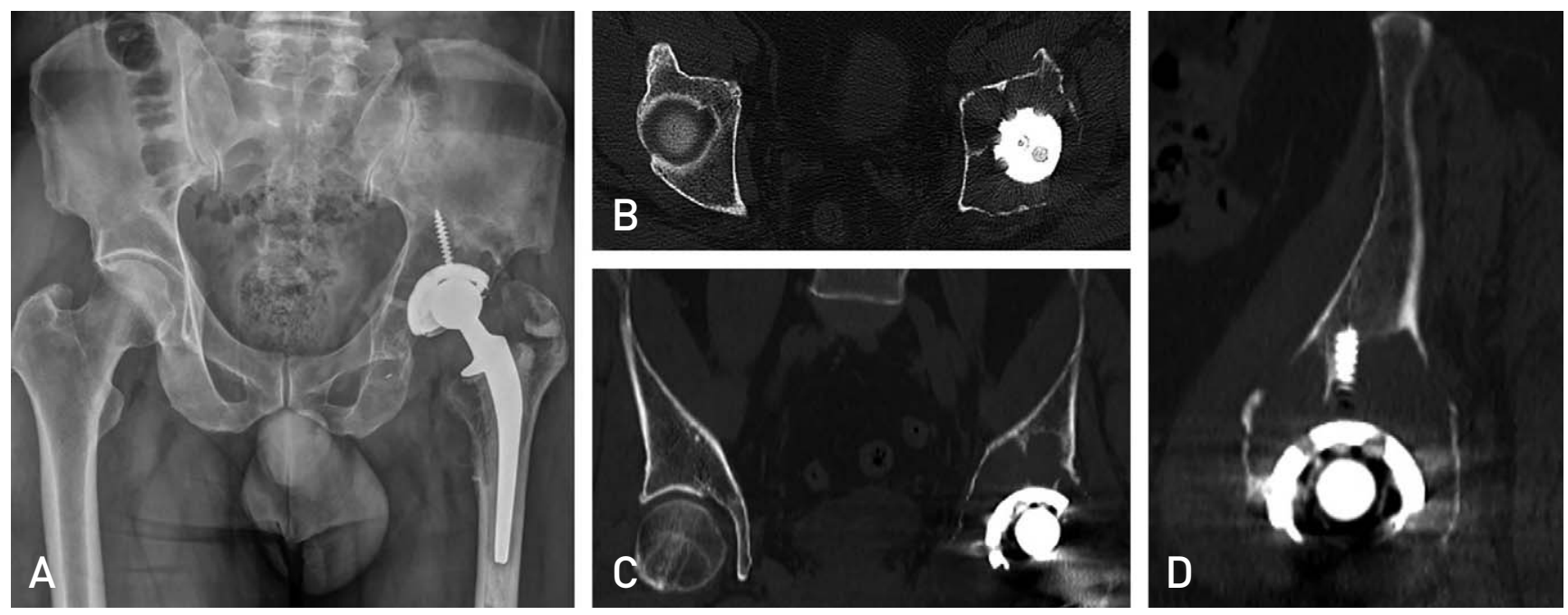

Fig. 2. (A-D) Radiograph and computed tomography images 12-year post hybrid total hip arthroplasty in a 47-year-old male patient revealing excessive wear and pelvic lysis. 


\section{Hip \& Pelvis}

Won Yong Shon et al. Total Hip Arthroplasty: Past, Present, and Future. What Has Been Achieved?
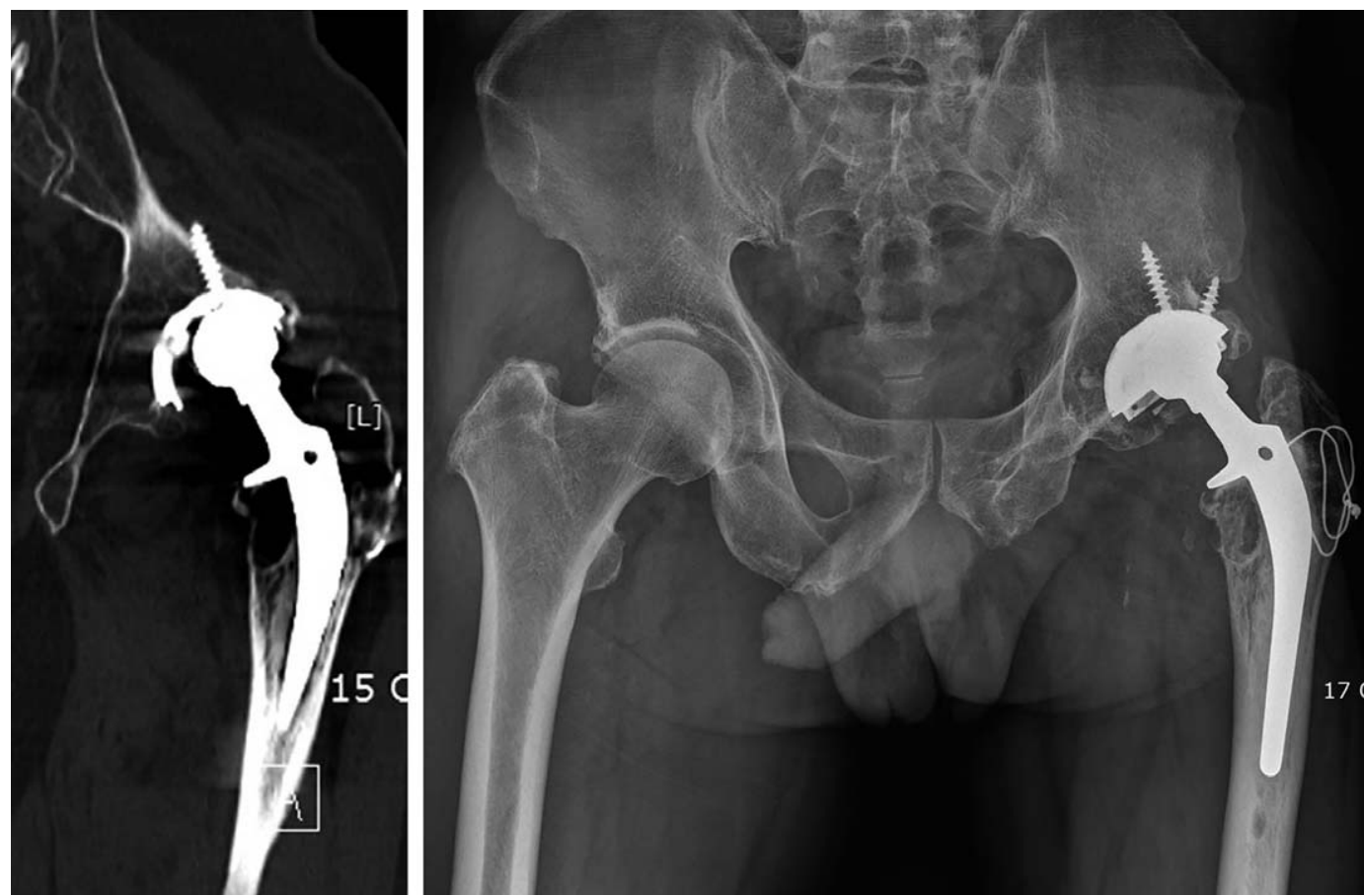

Fig. 3. Computed tomography image and anteroposterior hip radiography 24-years post hybrid total hip arthroplasty in a 55year-old male patient revealing excessive polyethylene liner wear and periacetabular lysis in the left hip joint.
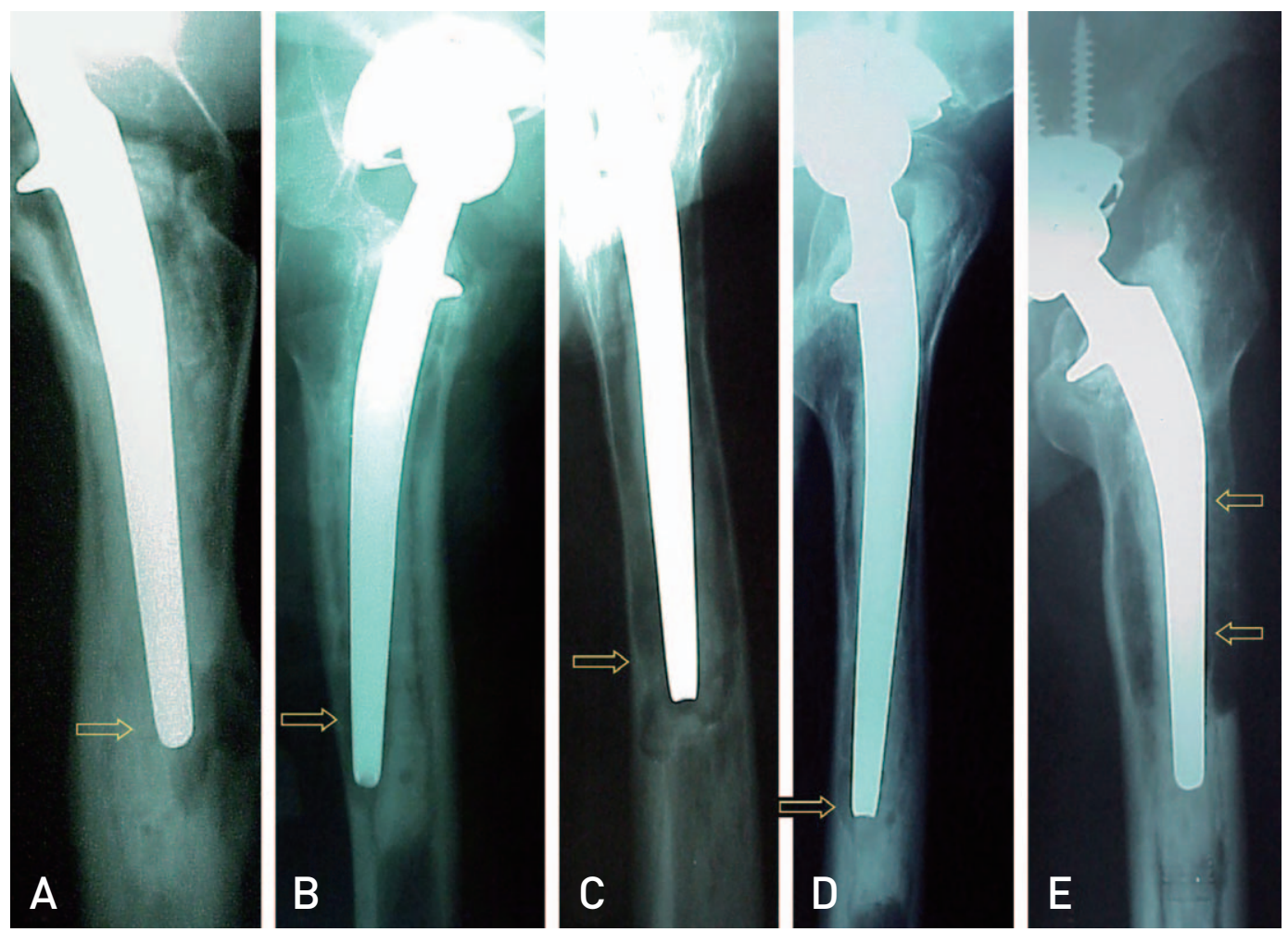

Fig. 4. (A-E) Postoperative radiographic images. Arrows show distal cement mantle defects with osteolysis. 


\section{Hip \& Pelvis}

Hip Pelvis 31(4): 179-189, 2019

demonstrated poor $\mathrm{C} 2$ cement grade $(P<0.001)$ (Fig. 4$)$. The mantles of cement in the femur were graded on early postoperative radiographs, according to previously reported criteria $^{14}$. Scoring is as follows: the cementing technique resulted in incomplete filling of the proximal portion of the medullary canal of the diaphysis, a so-called 'white-out' at the cement-bone interface (Grade A); the distribution of cement is nearly complete, but it is possible to distinguish cortical bone from cement in some areas (Grade B); extensive radiolucent line (more than 50 percent of the cement-bone interface) or voids in the cement (Grade C1); either a thin (less than one millimeter) mantle of cement at any site or a defect in the mantle of cement, with the metal in direct contact with the cortical bone (Grade C2) and any gross deficiencies in the mantle of cement, such as the presence of no cement, distal to the tip of the stem or major defects in the mantle of cement or multiple large voids (Grade D). Early failure of the cemented femoral stems in the author's early series was mainly due to an inefficient cementing technique and the use of Precoat stems ${ }^{14,19}$. It was also observed that patients having a cement grade of $\mathrm{C} 2$ had more subsidence when compared to patients with other cement grades. Furthermore, most stem failures occurred at the cement-bone interface despite the fact that Precoat stems strengthens the stemcement interface. This was a so-called "cement-bone

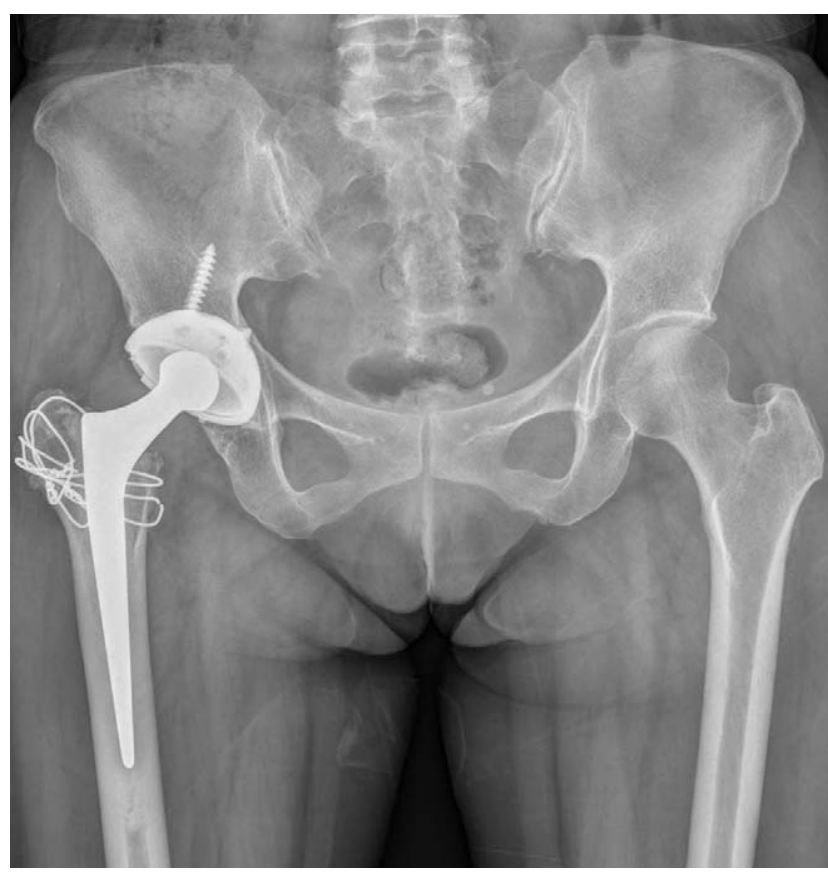

Fig. 5. Anteroposterior hip radiography 27 -year post hybrid total hip arthroplasty in a 48-year-old female patient revealing excellent radiological results. interface failure" because both the stem and cement became a lump and subsided in the medullary cavity of the femur. However, Precoat stems with a good cement mantle, have survived for more than 20 to 25 years, even in young patients (Fig. 5).

In 2007-2008, the author received a research grant from the Korea Food and Drug Administration (KFDA) and conducted research focused on the issues of polyethylene wear and wear-related osteolysis ${ }^{26-29}$. The author noted that the Harris-Galante cups revealed clear lysis in the hip, which was observed in anteroposterior and both oblique radiographs, at an average of 8 years after surgery; the annual wear rate of conventional non-cross-linked UHMWPE was found to be $0.175 \mathrm{~mm} / \mathrm{yr}$. The correlation between osteolysis volume in computed tomography (CT) and the area of osteolysis on a radiograph and polyethylene linear wear were also assessed by the author revealing that the sensitivity and specificity of anteroposterior radiographs for detection of osteolysis were $57.6 \%$ and $92.9 \%$, respectively. The addition of oblique radiographs increased the sensitivity to $64.4 \%$ without changing the specificity. The sensitivity of simple radiographs increased to $92.8 \%$ for a lesion more than $1,000 \mathrm{~mm}^{3}$. In the author's cases, there was pronounced pelvic lysis of about $25 \%$ at 8 years, $50 \%$ at 10 years, and $75 \%$ at 11 to 12 years after surgery (Fig. 6). In a comparative study between radiographs and 3-dimensional $\mathrm{CT}^{29}$, plain radiographs were found to be equally useful when screening for clinically significant osteolysis. In other CT-based studies ${ }^{27,30}$, the authors suggested the extent of the pelvic osteolytic volume on CT (Fig. 7) as a guide of the decision-making for treatment in patients who present with evidence of pelvic osteolysis which was noted to be accelerated in active

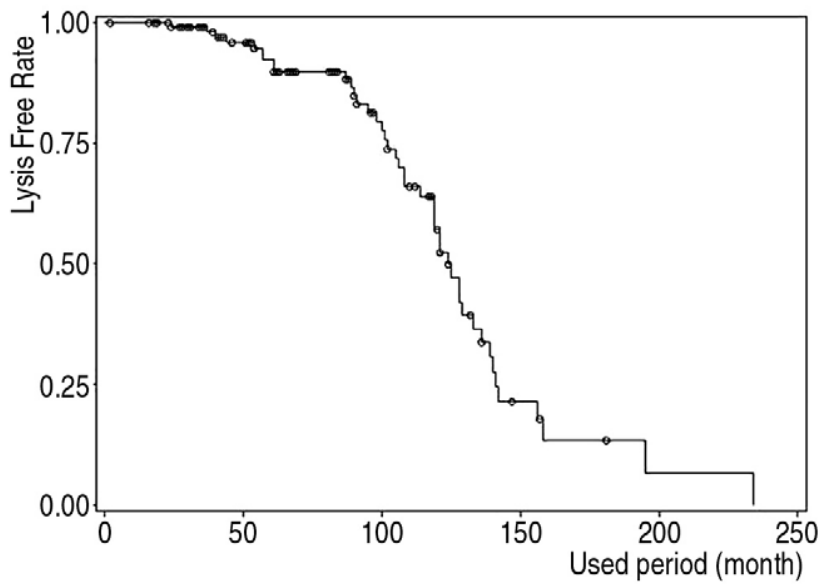

Fig. 6. Lysis free rate with time. 


\section{Hip \& Pelvis}

Won Yong Shon et al. Total Hip Arthroplasty: Past, Present, and Future. What Has Been Achieved?

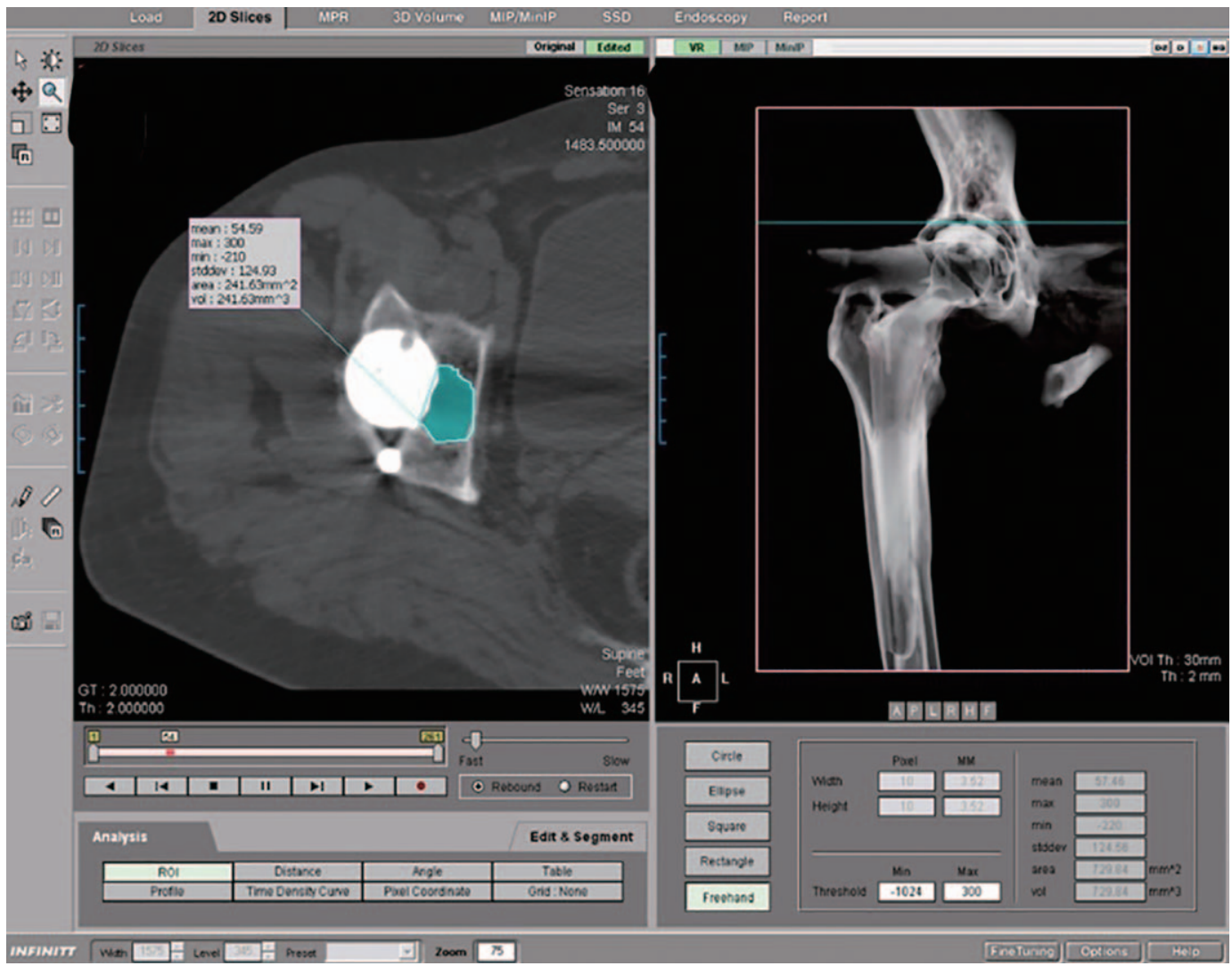

Fig. 7. A screenshot revealing osteolysis volume measurement on computed tomography using Rapidia 2.8 software.

young patients in the early stage.

In summary, the authors' past experiences using hybrid THAs have been disappointing because of poorly designed implants, undersized femoral components, poor cementing techniques, periprosthetic osteolysis, and excessive wear of the polyethylene liner.

\section{THE PRESENT}

To address the issues raised by the author in his earlier experiences, from 2000 the author began to use a secondgeneration acetabular cup (Trilogy; Zimmer, USA) which had: i) an improved liner locking system when compared to the first-generation acetabular cups, ii) a polished tapered femoral stem (Polished Versys Heritage; Zimmer), and iii) a highly cross-linked polyethylene liner (Longevity; Zimmer). Additionally, the author used a proximal and distal centralizer on the stem to prevent a grade $\mathrm{C} 2$ cement mantle defect.

In the author's study of 95 primary hybrid THAs with an average follow-up of 10 years $^{31)}$, the Harris hip score (HHS) improved from preoperative 58.9 points to postoperative 91.7 points. Cementing grades for the 95

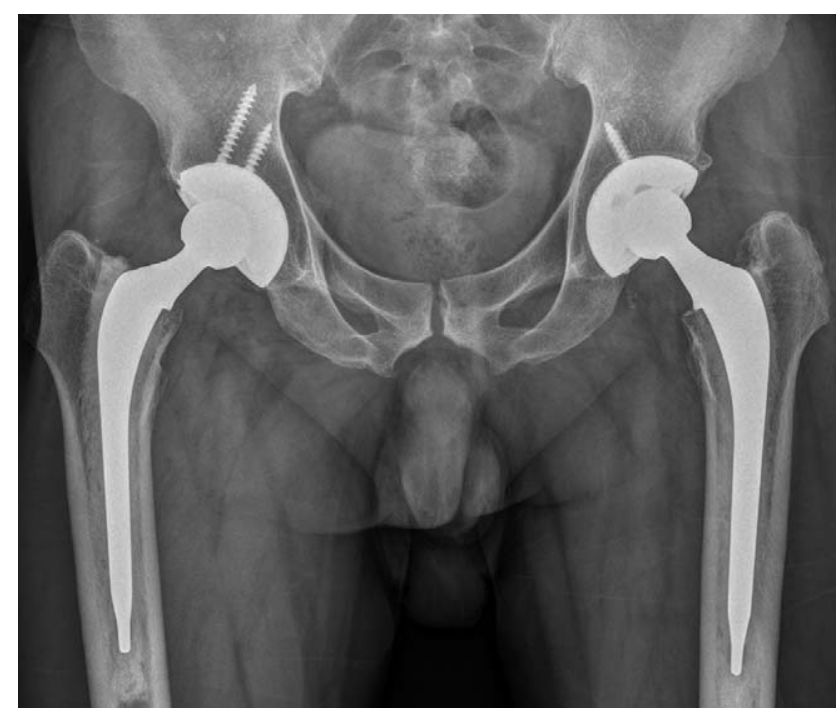

Fig. 8. Anteroposterior hip radiography 17-year post bilateral hybrid total hip arthroplasty in a 50-year-old male patient revealing excellent radiological results.

hips were Grade A $(n=45 ; 47.3 \%)$, Grade B $(n=48$; $50.5 \%)$, and Grade $\mathrm{C} 1(\mathrm{n}=2 ; 2.1 \%)$. There was one case of definite cup loosening $(1.0 \%)$ due to periprosthetic joint infection (PJI), however, periacetabular osteolysis 


\section{Hip \& Pelvis}
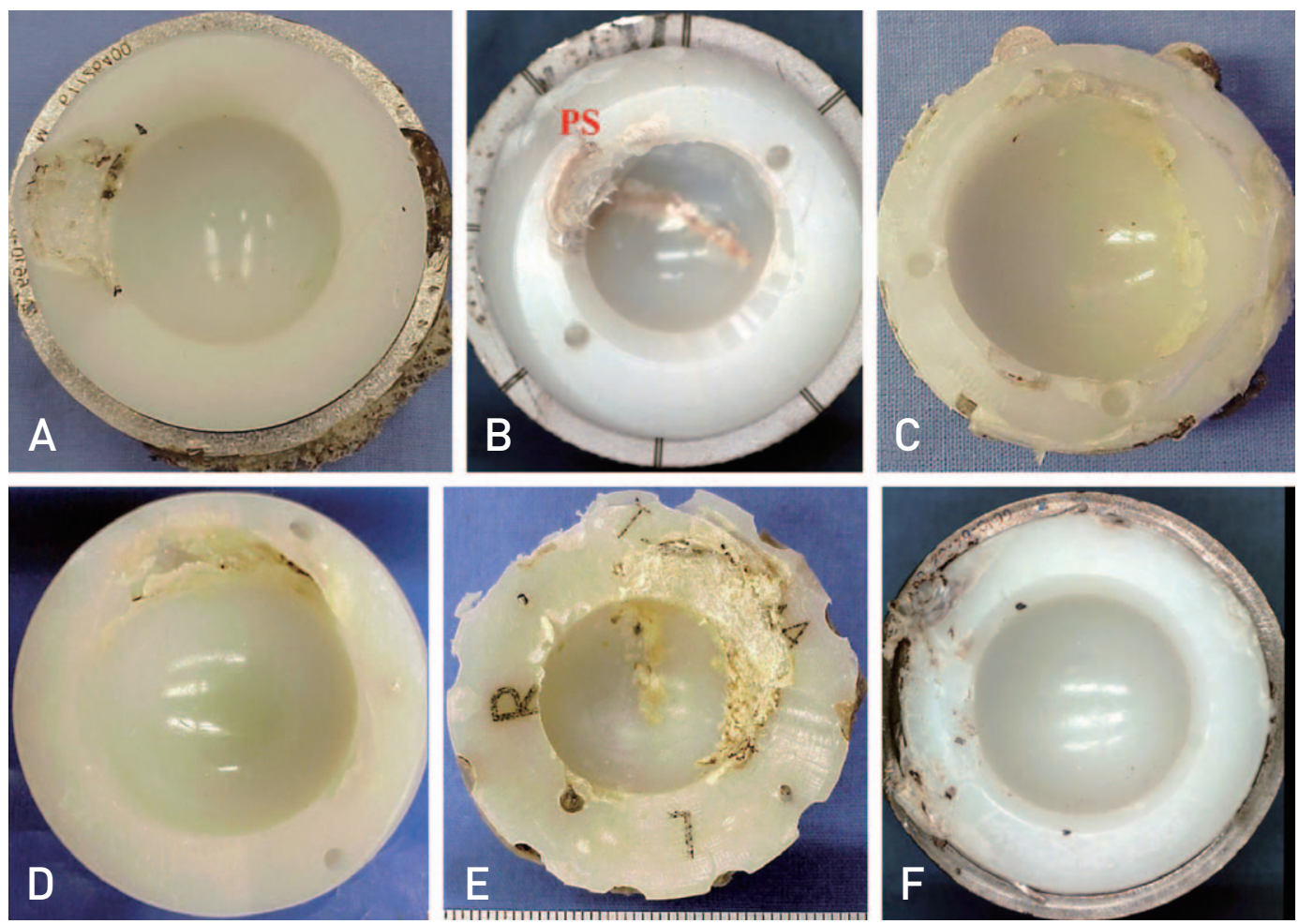

Fig. 9. (A-F) Retrieved polyethylene liners revealing rim damage extending across the entire rim.

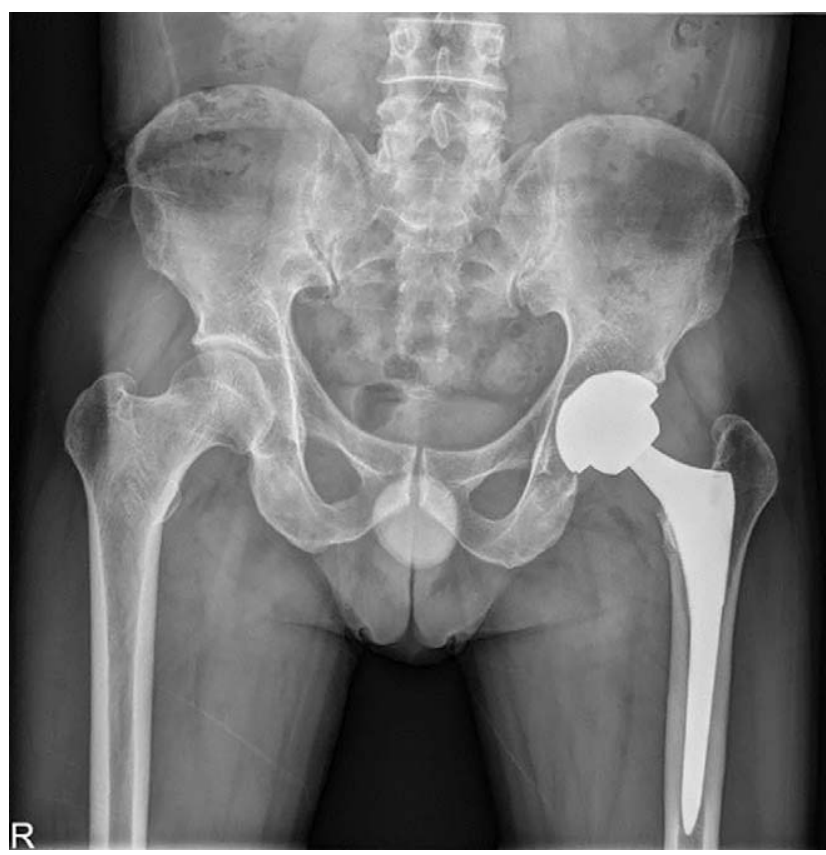

Fig. 10. Anteroposterior hip radiography 4-year post ceramicon-metal bearing total hip arthroplasty in a 51-year old male patient revealing excellent radiological results.

was not observed in these 95 cases. We extended this series to 152 hips (132 patients), with an average of 10 years follow-up (range, 6 to 16 years) in 2016. The clinical results were similar to those in the previous study ${ }^{31}$ and there were no reoperations. None of the hips revealed definite lysis on simple radiographs (anteroposterior and both oblique) of the pelvis and femur in this series. The excellent results obtained in this study (Fig. 8) were attributed to the use of a second-generation acetabular cup with highly cross-linked polyethylene liner, a polished surface stem with an improved cementing technique, and an appropriately sized femoral stem. When measured using the Polyware software (Draftware Inc., North Webster, IN, USA), the annual wear rate for highly cross-linked polyethylene liner and conventional non-cross-linked polyethylene liner was found to be $0.048 \mathrm{~mm} / \mathrm{yr}$ and $0.080 \mathrm{~mm} / \mathrm{yr}$, respectively. These results were similar to other studies ${ }^{32,33)}$, revealing that the annular linear wear for highly cross-linked UHMWP was about one-third or less than half when compared to that of the conventional polyethylene liners.

Due to the high incidence of impingement after THA $^{34}$ (Fig. 9), the author started using larger femoral heads $(36 \mathrm{~mm})$ to prevent impingement between the rim of the acetabular cup and the neck of the femoral stem. In 2001, ceramic-on-metal (COM) bearing surfaces were first introduced by John Fisher ${ }^{35}$. The advantages of COM are the reduced possibility of liner fracture and the ability to 
Won Yong Shon et al. Total Hip Arthroplasty: Past, Present, and Future. What Has Been Achieved?

use a femoral head of $36 \mathrm{~mm}$ or more. In a comparative in vitro and in vivo study ${ }^{36)}$, the performance of COM bearings was found to be superior to metal-on-metal or ceramic-on-ceramic (COC) couples. The author began to use COM (36 mm Biolox delta ceramic head and Ultamer metal liner) (Fig. 10) in 2009. In the author's analysis of 162 primary COM THAs with a mean of 4 years follow-up (range, 2-7 years), there were no cases of adverse local $^{37)}$ or systematic ${ }^{38)}$ reactions, infections, or loosening. Average HHS was 94.8 points, and more importantly, $70 \%, 80 \%$, and $86 \%$ of the patients were able to naturally sit cross-legged, kneel and squat. In the author's clinical study ${ }^{39)}$, the results of 140 COM THAs were compared with 94 non-COM THAs and it was noted that the COM group treated with $36 \mathrm{~mm}$ femoral heads had a higher HHS than the non-COM group treated with $28 \mathrm{~mm}$ femoral heads $(P=0.013)$. Furthermore, the total hip joint range of motion (ROM) was significantly greater in the COM group compared with the non-COM group $(P<0.001)$. The author also compared the metal ion levels in patients who could sit cross-legged, kneel, and squat with those who could not do the same in the COM group. It was observed that the serum cobalt ion levels in the patients who could squat were significantly higher compared with those in the patients who could not squat $(P=0.033)$. Similarly, the serum cobalt and chromium ion levels of the patients who could kneel were significantly higher compared with those patients who could not kneel $(P=0.049$ and 0.031$)$. Although the serum metal ion concentration was well below the concentration that could have a detrimental effect on the human body, significantly higher levels of cobalt and chromium concentrations were detected in the COM THA group compared with those of the non-COM THA group. Patients with a COM THA were capable of a greater ROM to suite the Asian lifestyle (i.e., the ability to sit cross-legged, kneel, and squat) were at risk of metal ion-related problems even with a $36 \mathrm{~mm}$ femoral head. In summary, there was no cases of metal-ion related problems observed in primary COM THA with $36 \mathrm{~mm}$ femoral heads. However, the author experienced a case of pseudotumor formation with acetabular cup aseptic loosening after revision COM THA ${ }^{40}$. Patients who underwent 36-mm COM THAs also experienced favorable clinical outcomes, with an improved hip function at short-term and midterm follow-ups but higher circulating $\mathrm{Co}$ and $\mathrm{Cr}$ ion levels compared with patients who underwent non-COM THAs. The serum metal ion levels and metal ion-related complications require additional investigation with a longer follow-up period, to better elucidate the influence of an Asian lifestyle on metal ion-related complications, such as muscle necrosis, osteolysis, pseudotumor, and hypersensitivity reaction.

Between 2002 and 2017, and before the author retired, data from a total of 1,557 primary THAs were available from Korea University Guro Hospital in South Korea. There were three cases $(0.19 \%)$ of femoral stem revision, 30 cases $(1.9 \%)$ of PJI treated with aggressive early debridement $(n=26 ; 1.7 \%)$, or revision surgery $(n=4$; $0.26 \%)$. Additionally, four cases $(0.26 \%)$ of dislocation were noted along with two cases $(0.13 \%)$ of periprosthetic fracture. Of the 1,557 cases in 16 years, only 41 cases (2.6\%) underwent reoperations or revisions for any cause. The author's results are similar to other established studies using national joint registries ${ }^{41,42}$, revealing that the incidence of 15-year survival rate in THAs' in the 1990s was about $75-80 \%$. However, when assessed in 2017 , the survival rate of THA after 1998 was greater than $90 \%$, hence it is evident that over time, loosening and revisions related to osteolysis continue to increase in the group where conventional non-cross-linked UHMWPE liners were used, whereas it has stayed at $1 \%$ even after 15 years in the group where highly cross-linked UHMWPE liners was used. Although PJI, dislocation, and periprosthetic fracture are common reasons for reoperation after THA, advancements in surgical techniques, tribology of the implants and improvement in the fixation techniques have greatly improved the long-term survival of the implants at present. The promising results of successful implant survival and improvement in a patient-reported outcome further suggests that THA is a feasible option, even in young patients with severe symptoms at the author's institute.

\section{THE FUTURE}

Several areas are expected to play larger roles in the future of THAs. Current THAs with alternative bearings (highly cross-linked polyethylene or ceramics) have provided excellent mid-term and long-term results. Hence, we can now focus on functional outcome improvements following THAs, especially in the Asian population-a group whose lifestyle varies greatly compared with the western population. Therefore, hip surgeons must be aware of advances in surgical techniques and the evidence behind implant selection as well as the continual improvement in the functional outcomes of this procedure to maximize longevity of the prosthesis. In Asia, these 
surgeries must be conducted with lifestyles of the population in mind (e.g., sitting on the floor, sitting cross-legged, kneeling) as these behaviors directly relate to a patient quality of life, thus serving as an important parameter in the clinical outcomes after THA. Hence, findings such as improvement in ROM resulting from the use of $36 \mathrm{~mm}$ heads compared with $28 \mathrm{~mm}$ heads (Table 1) and a significant difference in the clinical results between the groups for sitting cross-legged, squatting, and kneeling (Table 2) must be duly noted.

However, if patients are performing activities that increase ROM after THAs, impingement may occur between the cup liner and femoral stem, in current THA designs (Fig. 11). Impingement in THAs was observed in $27-84 \%$ of THA patients in retrieval studies (Fig. 12), which was well within the range observed in the author's retrieval study ${ }^{34}$. Even though the position of the cup and stem had been well placed within the safe zone, rim damage due to impingement was observed in over 50\% of cases The high incidence of impingement after THA implies that the functional outcomes of current THA designs lacks the ability to perform all daily physical activities which are needed to satisfy the demands of an Asian population. Changes in the implant design (e.g., avoiding skirted heads, maximizing the head-to-neck ratio, using a chamfered acetabular liner and a trapezoidal neck cross-section) may help reduce the prevalence of impingement ${ }^{34}$.

With regard to bearing surfaces from a global perspective, the recent trends and epidemiology of bearing surface usage in primary THAs in South Korea vary compared those in other countries ${ }^{43-45}$, including the use of a COC bearing surface-the most prevalent articulation regardless of patient's age and hospital amounting to up to $80 \%$ of total bearing surface cases ${ }^{46}$. This is in contrast to the trend in the USA ${ }^{43,44}$, where the COC bearing is only used in $4 \%$ of cases, whereas the polyethylene liner is used most often (92\% of cases). This tendency is similar to what has been reported in Europe ${ }^{45}$. The choice of bearing surface may be affected by many factors, which includes the nation's medical delivery system, payment type, disease pattern and age distribution of patients that undergo THA. In the future, the results of a large-scale multi-national study on bearing surfaces must be reported. A more thorough

Table 1. The Range of Motion and Postoperative HHS between $36 \mathrm{~mm}$ COM Group and $28 \mathrm{~mm}$ Non-COM Group

\begin{tabular}{lccc}
\hline \hline Variable & 36 mm COM group & 28 mm non-COM group & $P$-value \\
\hline Flexion $\left({ }^{\circ}\right)$ & $123.1 \pm 16.8$ & $116.0 \pm 16.2$ & 0.002 \\
Abduction $\left({ }^{\circ}\right)$ & $43.8 \pm 10.6$ & $39.9 \pm 9.6$ & 0.018 \\
Adduction $\left({ }^{\circ}\right)$ & $33.5 \pm 8.6$ & $29.7 \pm 9.5$ & 0.006 \\
External rotation $\left({ }^{\circ}\right)$ & $39.9 \pm 8.9$ & $35.6 \pm 8.7$ & 0.009 \\
Internal rotation $\left({ }^{\circ}\right)$ & $32.4 \pm 10.0$ & $27.2 \pm 9.8$ & 0.001 \\
Total range of motion $\left({ }^{\circ}\right)$ & $272.7 \pm 30.7$ & $248.5 \pm 32.3$ & $<0.001$ \\
Postoperative HHS (points) & $95.4 \pm 5.4$ & $93.2 \pm 6.4$ & 0.013 \\
\hline
\end{tabular}

Values are presented as mean \pm standard deviation.

HHS: Harris hip score, COM: ceramic-on-metal.

Table 2. The Clinical Outcomes between the Groups with Sit Cross-legged, Squat, and Kneel and Those without within the Same $36 \mathrm{~mm}$ Head

\begin{tabular}{lccc}
\hline \hline Variable & Number & Postoperative HHS (points) & \\
\hline Sit cross-legged & & & 0.012 \\
$\quad$ Negative & 57 & 91.6 & \\
$\quad$ Positive & 129 & 96.0 & 0.001 \\
Squat & & & \\
$\quad$ Negative & 40 & 91.8 & \\
Positive & 149 & 95.6 & \\
Kneel & & 90.1 & \\
Negative & 25 & 95.3 & \\
Positive & 166 & & \\
\hline
\end{tabular}

HHS: Harris hip score. 


\section{Hip \& Pelvis}

Won Yong Shon et al. Total Hip Arthroplasty: Past, Present, and Future. What Has Been Achieved?

understanding of the kinematics of the hip joint after THA is required since we do not completely understand this parameter in dynamic post-THA situation. Ongoing insights in hip kinematics ${ }^{47,48}$ after THA may improve the prosthetic function and patient satisfaction as well as simplify bearing surface decisions while increasing component lifespan.
Recent studies on the spinopelvic motion ${ }^{49-52)}$ based on hipspine relations ${ }^{53)}$ also suggest that our conventional knowledge of risk factors for dislocation may need to be revisited. Acetabular cup implantation ideally must be adapted depending on spinopelvic interactions, thereby lowering the rate of impingement and subsequent dislocation.
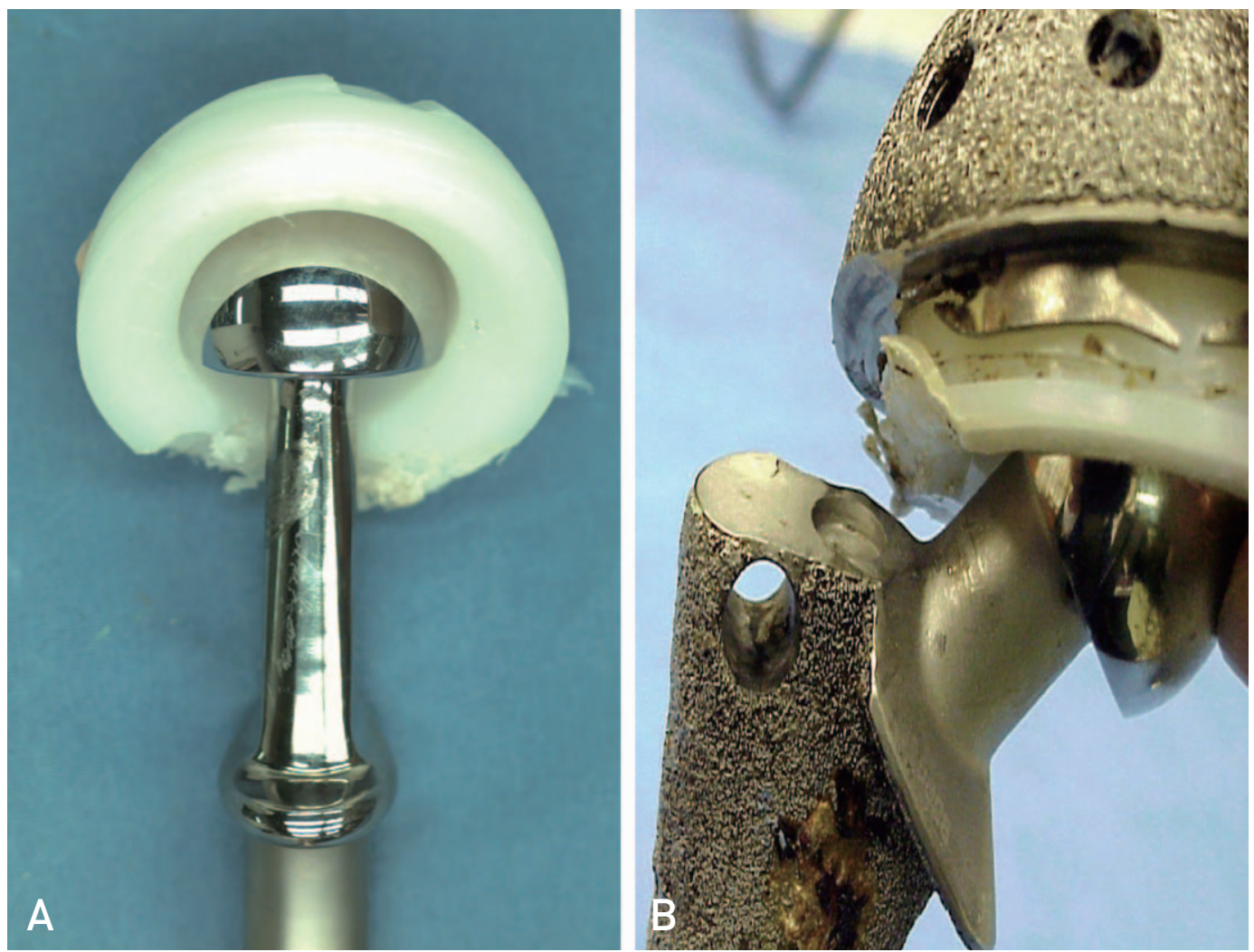

Fig. 11. (A, B) Retrieved acetabular and femoral components from a 43-year--old male patient revealing polyethylene liner damage by impingement between the rim of polyethylene liner and neck of the femoral stem.
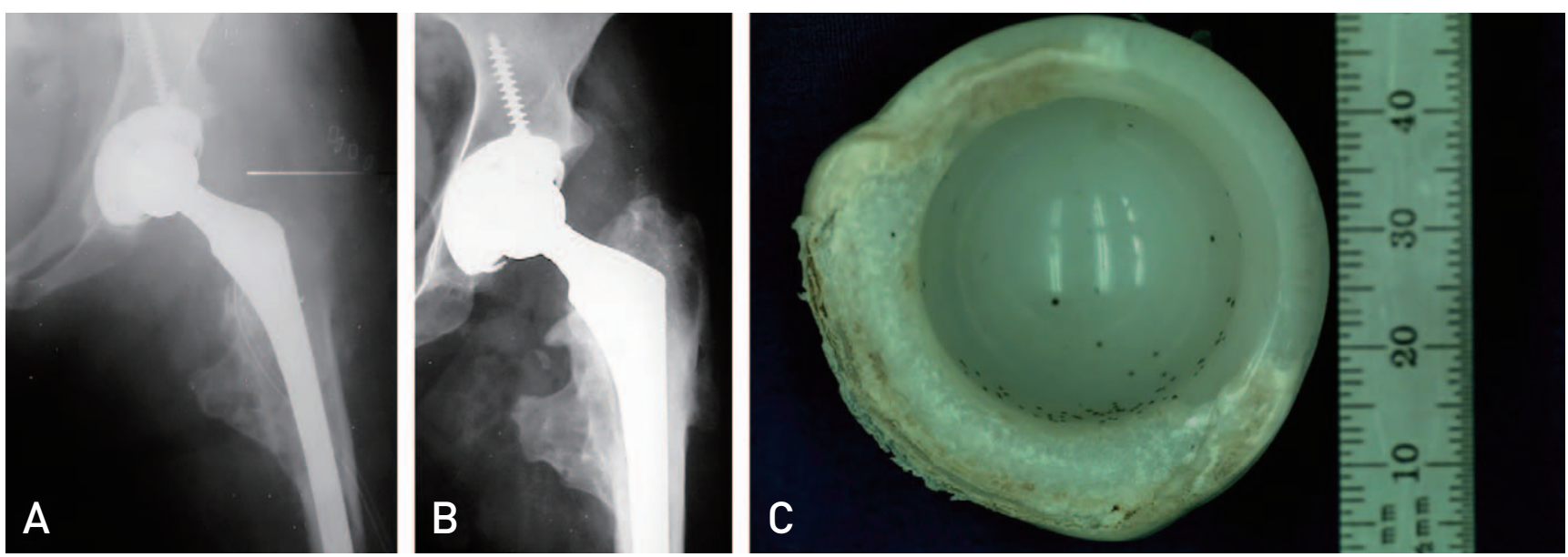

Fig. 12. Hip anteroposterior radiographs (A, B) and a clinical photo (C) of a 32-year-old male patient revealing polyethylene liner wear and damages by impingement. 
The current THA design model is tailored to the lifestyle of patients in Western countries, and most research on health-related quality of life of THA patients is from Western countries. Future research should be focused on assessing the living conditions of THA patients and their lifestyles to improve health-related quality of life in Asian countries $^{54-56)}$. Furthermore, a new scoring system, which can assess the clinical, functional and quality of life after THA should be addressed.

\section{CONCLUSION}

Although the early results of THAs have been disappointing, there have been steady advances in the last three decades. Currently, THA is a landmark surgery in modern medical history and clinical results from the last 30 years have proven THA to be one of the most successful surgical techniques for treating degenerative conditions of the hip. Our results support the use of current THA as a feasible option, even in young patients with severe symptoms.

The future of THA must not only focus on improvement in the physical function, but also the daily quality of life, including that of the Asian population. Dynamic kinematics after THA should be better understood, including its effect on each bearing surface. A new scoring system is needed, which can assess the clinical, functional and quality of life to improve outcomes after THA in the Asian population.

\section{CONFLICT OF INTEREST}

The authors declare that there is no potential conflict of interest relevant to this article.

\section{REFERENCES}

1.Law WA. Post-operative study of vitallium mould arthroplasty of the hip joint. J Bone Joint Surg Br. 1948;30:76-83.

2. Smith-Petersen MN. Evolution of mould arthroplasty of the hip joint. J Bone Joint Surg Br. 1948;30:59-75.

3. Charnley J. Anchorage of the femoral head prosthesis to the shaft of the femur. J Bone Joint Surg Br. 1960;42:2830 .

4. Charnley J. Arthroplasty of the hip. A new operation. Lancet. 1961;1:1129-32.

5. Amstutz HC, Campbell P, Kossovsky N, Clarke IC. Mechanism and clinical significance of wear debris-induced osteolysis. Clin Orthop Relat Res. 1992;(276):7-18.

6. Chandler HP, Reineck FT, Wixson RL, McCarthy JC. Total hip replacement in patients younger than thirty years old. A five-year follow-up study. J Bone Joint Surg Am. 1981;
63:1426-34.

7. Collis DK. Cemented total hip replacement in patients who are less than fifty years old. J Bone Joint Surg Am. 1984; 66:353-9.

8. Cooper RA, McAllister CM, Borden LS, Bauer TW. Polyethylene debris-induced osteolysis and loosening in uncemented total hip arthroplasty. A cause of late failure. J Arthroplasty. 1992;7:285-90.

9. Goetz DD, Smith EJ, Harris WH. The prevalence of femoral osteolysis associated with components inserted with or without cement in total hip replacements. A retrospective matched-pair series. J Bone Joint Surg Am. 1994;76:1121-9.

10. Gruen TA, McNeice GM, Amstutz HC. "Modes of failure" of cemented stem-type femoral components: a radiographic analysis of loosening. Clin Orthop Relat Res. 1979;141: 17-27.

11. Phillips FM, Pottenger LA, Finn HA, Vandermolen J. Cementless total hip arthroplasty in patients with steroidinduced avascular necrosis of the hip. A 62-month followup study. Clin Orthop Relat Res. 1994;(303):147-54.

12. Salvati EA, Cornell CN. Long-term follow-up of total hip replacement in patients with avascular necrosis. Instr Course Lect. 1988;37:67-73.

13. Reese A, Macaulay W. Hybrid total hip arthroplasty: stateof-the-art in the new millennium? J South Orthop Assoc. 2003; $12: 75-8$.

14. Suh DH, Yun HH, Chun SK, Shon WY. Fifteen-year results of precoated femoral stem in primary hybrid total hip arthroplasty. Clin Orthop Surg. 2013;5:110-7.

15. Smith SE, Estok DM 2nd, Harris WH. Average 12-year outcome of a chrome-cobalt, beaded, bony ingrowth acetabular component. J Arthroplasty. 1998;13:50-60.

16. Kim YH, Kim JS, Cho SH. Primary total hip arthroplasty with a cementless porous-coated anatomic total hip prosthesis: 10- to 12-year results of prospective and consecutive series. J Arthroplasty. 1999;14:538-48.

17. Clohisy JC, Harris WH. The Harris-Galante porous-coated acetabular component with screw fixation. An average tenyear follow-up study. J Bone Joint Surg Am. 1999;81:66-73.

18. Maloney WJ, Galante JO, Anderson M, et al. Fixation, polyethylene wear, and pelvic osteolysis in primary total hip replacement. Clin Orthop Relat Res. 1999;(389):157-64.

19. Ong A, Wong KL, Lai M, Garino JP, Steinberg ME. Early failure of precoated femoral components in primary total hip arthroplasty. J Bone Joint Surg Am. 2002;84:786-92.

20. Charnley J. Total hip replacement by low-friction arthroplasty. Clin Orthop Relat Res. 1970;72:7-21.

21. Sochart DH, Porter ML. The long-term results of Charnley low-friction arthroplasty in young patients who have congenital dislocation, degenerative osteoarthrosis, or rheumatoid arthritis. J Bone Joint Surg Am. 1997;79:1599-617.

22. Jones LC, Hungerford DS. Cement disease. Clin Orthop Relat Res. 1987;(225):192-206.

23. Chen FS, Di Cesare PE, Kale AA, et al. Results of cemented metal-backed acetabular components: a 10-year-average follow-up study. J Arthroplasty. 1998;13:867-73.

24. Clarke IC, Good V, Anissian L, Gustafson A. Charnley wear model for validation of hip simulators--ball diameter versus polytetrafluoroethylene and polyethylene wear. Proc 
Won Yong Shon et al. Total Hip Arthroplasty: Past, Present, and Future. What Has Been Achieved?

Inst Mech Eng H. 1997;211:25-36.

25. Parks ML, Walsh HA, Salvati EA, Li S. Effect of increasing temperature on the properties of four bone cements. Clin Orthop Relat Res. 1998;(355):238-48.

26. Yun HH, Shon WY, Yoon JR, Yang JH, Lim DS. Reliability of a PowerPoint method for wear measurement after total hip arthroplasty: a retrieval study using 3-dimensional laser scanning. J Arthroplasty. 2012;27:1530-7.

27. Yun HH, Shon WY, Hong SJ, Yoon JR, Yang JH. Relationship between the pelvic osteolytic volume on computed tomography and clinical outcome in patients with cementless acetabular components. Int Orthop. 2011;35:1453-9.

28. Yun HH, Jajodia NK, Myung JS, Oh JK, Park SW, Shon WY. Use of slide presentation software as a tool to measure hip arthroplasty wear. J Arthroplasty. 2009;24:1210-5.

29. Shon WY, Gupta S, Biswal S, Han SH, Hong SJ, Moon JG. Pelvic osteolysis relationship to radiographs and polyethylene wear. J Arthroplasty. 2009;24:743-50.

30. Suh DH, Han SB, Yun HH, Chun SK, Shon WY. Characterization of progression of pelvic osteolysis after cementless total hip arthroplasty: computed tomographic study. J Arthroplasty. 2013;28:1851-5.

31. JuYi JW, Shon WY, Huh CY, Yun HH, Huh YJ. Follow-up study of the cemented polished femoral stem for more than five years. Hip Pelvis. 2011;23:25-31.

32. McKellop H, Shen FW, Lu B, Campbell P, Salovey R. Development of an extremely wear-resistant ultra high molecular weight polyethylene for total hip replacements. J Orthop Res. 1999; 17:157-67.

33. Wroblewski BM, Siney PD, Fleming PA. Low-friction arthroplasty of the hip using alumina ceramic and crosslinked polyethylene. A 17-year follow-up report. J Bone Joint Surg Br. 2005;87:1220-1.

34. Shon WY, Baldini T, Peterson MG, Wright TM, Salvati EA. Impingement in total hip arthroplasty a study of retrieved acetabular components. J Arthroplasty. 2005;20:427-35.

35. Firkins PJ, Tipper JL, Ingham E, Stone MH, Farrar R, Fisher J. A novel low wearing differential hardness, ceramic-onmetal hip joint prosthesis. J Biomech. 2001;34:1291-8.

36. Williams S, Schepers A, Isaac G, et al. The 2007 Otto Aufranc Award. Ceramic-on-metal hip arthroplasties: a comparative in vitro and in vivo study. Clin Orthop Relat Res. 2007;465: 23-32.

37. Bisschop R, Boomsma MF, Van Raay JJ, Tiebosch AT, Maas M, Gerritsma CL. High prevalence of pseudotumors in patients with a Birmingham Hip Resurfacing prosthesis: a prospective cohort study of one hundred and twenty-nine patients. J Bone Joint Surg Am. 2013;95:1554-60.

38. Bozic KJ, Browne J, Dangles CJ, et al. Modern metal-onmetal hip implants. J Am Acad Orthop Surg. 2012;20:402-6.

39. Han SB, Oh JK, Jang WY, Choudhary N, Kim HG, Shon WY. Increased serum ion levels after ceramic-on-metal bearing total hip arthroplasty: influence of an Asian lifestyle. J Arthroplasty. 2018;33:887-92.

40. Naik LG, Shon WY, Clarke IC, Moon JG, Mukund P, Kim SM. Pseudotumor and subsequent implant loosening as a complication of revision total hip arthroplasty with ceramicon-metal bearing: a case report. Hip Pelvis. 2018;30:276-81.

41. Pearson MJ, Grover LM, Lord JM, Jones SW, Davis ET.
Bearings in hip arthroplasty: joint registries vs precision medicine: review article. HSS J. 2017;13:20-7.

42. Kasina P, Wall A, Lapidus LJ, et al. Postoperative thromboprophylaxis with new oral anticoagulants is superior to LMWH in hip arthroplasty surgery: findings from the Swedish registry. Clin Orthop Relat Res. 2019;477:1335-43.

43. Heckmann ND, Sivasundaram L, Stefl MD, Kang HP, Basler ET, Lieberman JR. Total hip arthroplasty bearing surface trends in the United States from 2007 to 2014: the rise of ceramic on polyethylene. J Arthroplasty. 2018;33: 1757-63.e1.

44. Rajaee SS, Theriault RV, Pevear ME, Smith EL. National trends in primary total hip arthroplasty in extremely young patients: a focus on bearing surface usage from 2009 to 2012. J Arthroplasty. 2016;31(9 Suppl):63-8.

45. Fawsitt CG, Thom HHZ, Hunt LP, et al. Choice of prosthetic implant combinations in total hip replacement: costeffectiveness analysis using $U K$ and Swedish hip joint registries data. Value Health. 2019;22:303-12.

46. Yoon PW, Yoo JJ, Kim Y, Yoo S, Lee S, Kim HJ. The epidemiology and national trends of bearing surface usage in primary total hip arthroplasty in Korea. Clin Orthop Surg. 2016;8:29-37.

47. Rivière C, Harman C, Parsons T, Villet L, Cobb J, Maillot C. Kinematic alignment versus conventional techniques for total hip arthroplasty: a retrospective case control study. Orthop Traumatol Surg Res. 2019; 105:895-905.

48. Komiyama K, Hamai S, Hara D, et al. Dynamic hip kinematics during squatting before and after total hip arthroplasty. J Orthop Surg Res. 2018;13:162.

49. Lum ZC, Coury JG, Cohen JL, Dorr LD. The current knowledge on spinopelvic mobility. J Arthroplasty. 2018; 33:291-6.

50. Stefl M, Lundergan W, Heckmann N, et al. Spinopelvic mobility and acetabular component position for total hip arthroplasty. Bone Joint J. 2017;99(1 Supple A):37-45.

51. Shon WY, Sharma V, Keon OJ, Moon JG, Suh DH. Can pelvic tilting be ignored in total hip arthroplasty? Int J Surg Case Rep. 2014;5:633-6.

52. Shon WY, Gupta S, Biswal S, et al. Validation of a simple radiographic method to determine variations in pelvic and acetabular cup sagittal plane alignment after total hip arthroplasty. Skeletal Radiol. 2008;37:1119-27.

53. Lazennec JY, Charlot N, Gorin M, et al. Hip-spine relationship: a radio-anatomical study for optimization in acetabular cup positioning. Surg Radiol Anat. 2004;26: 136-44.

54. Tang H, Du H, Tang Q, Yang D, Shao H, Zhou Y. Chinese patients' satisfaction with total hip arthroplasty: what is important and dissatisfactory? J Arthroplasty. 2014;29: 2245-50.

55. Fujita K, Kang HS, Mawatari M, Makimoto K, Lee M, Hwang J. Quality of life, effects on Asian lifestyle, and perceived satisfaction after total hip arthroplasty in Japan and Korea. Int J Orthop Trauma Nurs. 2018;31:20-5.

56. Fujita K, Xia Z, Liu X, Mawatari M, Makimoto K. Lifestyle and health-related quality of life in Asian patients with total hip arthroplasties. Nurs Health Sci. 2014;16: 365-72. 